\title{
Residual stress mapping in Inconel 625 fabricated through additive manufacturing: method for neutron diffraction measurements to validate thermomechanical model predictions
}

\author{
Zhuqing Wang ${ }^{1}$, Erik Denlinger ${ }^{2}$, Panagiotis Michaleris ${ }^{2}$, Alexandru D. Stoica ${ }^{3}$, Dong $\mathrm{Ma}^{3}$, \\ Allison M. Beese ${ }^{1 *}$ \\ ${ }^{1}$ Department of Materials Science and Engineering, Pennsylvania State University, University \\ Park, PA, 16802, USA \\ ${ }^{2}$ Autodesk Inc., State College, PA 16803, USA \\ ${ }^{3}$ Chemical and Engineering Materials Division, Neutron Sciences Directorate, Oak Ridge \\ National Laboratory, Oak Ridge, Tennessee 37831, USA. \\ "Corresponding author email: amb961@ psu.edu
}

\begin{abstract}
The rapid solidification and subsequent thermal cycles that material is subjected to during additive manufacturing (AM) of a component result in a buildup of residual stresses, which lead to part distortion, and negatively impact the component's mechanical properties. We present a method for using neutron diffraction to validate thermomechanical models developed to predict the residual stresses in Inconel 625 walls fabricated by laser-based directed energy deposition. Residual stress calculations from neutron diffraction measurements depend strongly on the determination of stress-free lattice spacings. After measurement of stressed lattice spacings in Inconel 625 walls, reference samples were obtained by extracting thin slices from the walls and cutting comb-type slits into these slices. Reference lattice spacings were measured in these
\end{abstract}


slices, as well as equivalent slices that were also subjected to stress-relieving heat treatment. These heat treatments changed the reference lattice spacings, and therefore affected residual strain measurements. Further, this study shows the importance of using location-dependent reference lattice spacing, as during AM, the thermal history, and therefore elemental composition and stress-free lattice spacing, vary with position. Residual stresses measured by neutron diffraction along the build direction using comb-type reference samples without heat treatment were in good agreement with thermomechanical modeling predictions.

Keywords: Additive manufacturing, Inconel 625, residual stress, neutron diffraction, thermomechanical modeling

\section{Introduction}

In additive manufacturing (AM), 3-dimensional metallic alloy components are fabricated layer by layer, from metal wire or powder feedstock. The feedstock is melted by a laser or electron beam and undergoes solidification and fusion to the layer below [1-4]. Each location in the deposited component undergoes initial rapid solidification and is subjected to repeated thermal cycles as additional layers are added, leading to the buildup of residual stresses that result in distortion of the component such that its geometry deviates from the required build dimensions or collisions of the sample and AM equipment during fabrication. In addition, residual stresses can lead to failure at lower than optimal applied stress levels, and may introduce micro-cracks that further reduce the strength and macroscopic mechanical performance of the component [5].

Residual stresses can be computed using computational models, but these models must be validated through quantitative measurements, including destructive and non-destructive 
experimental techniques. Hole drilling, a destructive technique involves applying strain gauges to the surface of a sample, drilling blind or through holes to relieve stresses, and computing the initial residual stresses from the elastic deformation that occurs when the hole is drilled and the stresses at the surface are relieved [6]. The contour method is another destructive technique, which involves cutting a sample into two, measuring the resulting deformations, and computing stresses using an accompanying finite element analysis [7]. Non-destructive methods, such as neutron and x-ray diffraction (XRD), are based on Bragg's law of diffraction in which the lattice spacing of specific sets of (hkl) planes, $d_{h k l}$, can be measured in stressed and stress-free samples. The $h k l$-specific lattice strain is calculated from the relative change in the stressed lattice plane spacing, $d_{h k l}$, with respect to reference, or stress-free spacing, $d_{h k l}^{0}$, and the residual stresses can be computed from these lattice strains.

Neutron diffraction, which is the focus of the present study, has been widely used in residual stress measurements due to the deep penetration of neutrons into metallic materials, which is on the order of $\mathrm{cm}$ [8]. Since a small deviation in reference lattice spacing can have a significant influence on the computed residual stresses, it is essential to identify and use an appropriate method to accurately measure $d_{h k l}^{0}$ in neutron diffraction. To determine stress-free lattice spacings, macroscopically stress-free samples can be obtained by cutting a small cube from the material of interest, on the order of $(2 \mathrm{~mm})^{3}$, or cutting the material into a comb pattern to relieve stresses [9-12]. For example, Thibault et al. [13] extracted a sample from a stainless steel weld and machined comb slits in the sample to relieve stresses. The reference $d_{h k l}^{0}$ can also be calculated by measuring $d_{h k l}$ in a direction in which stress is assumed to be zero or negligible.

For example, Moat et al. [14] studied a $5 \mathrm{~mm}$ thick Waspaloy wall made by AM, and found $d_{h k l}^{0}$ 
by measuring the $d_{h k l}$ in the thickness direction of the wall, along which they assumed the stresses were zero. Martinson et al. and Zhang et al. $[15,16]$ acquired $d_{h k l}^{0}$ by assuming stresses normal to the welding plane were zero in welded materials, and taking that measurement of $d_{h k l}$ as the reference lattice spacing. Another method for determining $d_{h k l}^{0}$ is to measure the stressed $d_{h k l}$ values within a component, and to solve for the necessary $d_{h k l}^{0}$ to satisfy equilibrium in the component [17].

The aim of the present study was to develop a method for measuring the residual stresses within two Inconel 625 walls fabricated by laser-based directed energy deposition (DED) additive manufacturing using two different processing conditions. Neutron diffraction was used to measure lattice strains and residual stresses, and these measurements were compared with those predicted by thermomechanical modeling. Multiple methods were used to obtain the stress-free location-dependent $d_{h k l}^{0}$ values via neutron diffraction, and the results from these methods were compared to those of the thermomechanical model to determine the best way for computing reference lattice spacing values and residual stresses using neutron diffraction.

\section{Experimental methods}

Four geometrically similar walls measuring $102 \mathrm{~mm}$ long x $7 \mathrm{~mm}$ thick x $28 \mathrm{~mm}$ tall were built by DED using prealloyed gas atomized Inconel 625 powder. The walls were deposited onto annealed Inconel 625 substrates measuring $152 \mathrm{~mm}$ x $38 \mathrm{~mm}$ x $13 \mathrm{~mm}$. An IPG Photonics YLR12000 laser was used to melt the powder at a laser power of $2 \mathrm{~kW}$ and a scanning speed of 10.6 $\mathrm{mm} / \mathrm{s}$. The powder was delivered by a Precitec YC-50 cladding head at a powder feed rate of 16 $\mathrm{g} / \mathrm{min}$ in an argon gas flow of $9.4 \mathrm{~L} / \mathrm{min}$. Two build conditions were used to determine the effect of processing conditions on residual stress and distortion: in one set of walls, after one 3-pass 
layer was deposited, a $40 \mathrm{~s}$ dwell time was added before building the next 3-pass layer to allow time for the build to cool, while in the other set of walls, the layers were deposited continuously, meaning the dwell time between subsequent 3-pass layers was $0 \mathrm{~s}$ [18]. Understanding the effect of dwell time on distortion accumulation is important, particularly as it relates to the deposition of large components, in which a significant amount of time would pass between the laser reaching one location again.

Neutron diffraction residual stress measurements were performed on VULCAN, the Engineering Diffractometer at the Spallation Neutron Source at Oak Ridge National Laboratory [19]. The fundamentals of time-of-flight neutron diffraction for residual stress measurements can be found in $[20,21]$ and the details of VULCAN's instrumentation have been described elsewhere [22,23]. Figure 1 shows the configurations used to measure thickness, height, and length strains along three principal directions in the additively manufactured walls. Two detector banks collected diffraction spectra from grains that had lattice planes perpendicular to scattering vectors $\mathrm{Q}_{1}$ and $\mathrm{Q}_{2}$ simultaneously, corresponding to lattice spacing along the thickness direction being collected by Bank 1 and lattice spacing along the height direction being collected by Bank 2. Samples were repositioned and scanned again to acquire the lattice spacings in the third orthogonal direction. In the second configuration, shown in Figure 1b, detector Bank 1 collected diffraction patterns for lattice spacings in the length direction. The configurations for measurement of $d_{h k l}^{0}$ values in the stress-relieved samples were the same, with diffraction patterns taken from stress-free lattice planes in the length and thickness directions. 

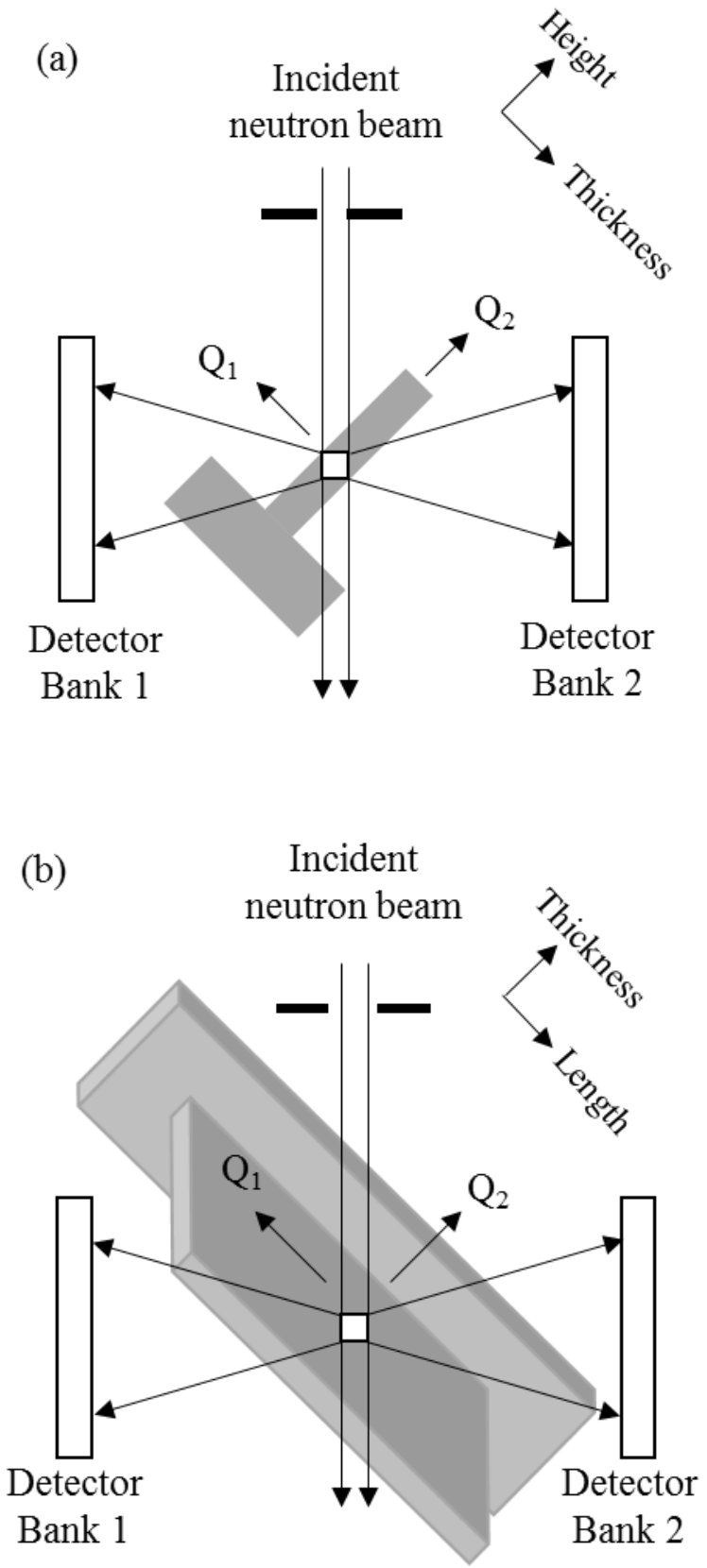

Figure 1. Schematic of neutron diffraction experimental set up with two different sample orientations. (a) Configuration used to measure height $\left(\mathrm{Q}_{2}\right)$ and thickness strains $\left(\mathrm{Q}_{1}\right)$, and (b) configuration used to measure length strains $\left(\mathrm{Q}_{1}\right)$.

The lattice spacings, $d_{h k l}$, were measured along the centerline of one wall made with $0 \mathrm{~s}$ dwell, and one wall made with $40 \mathrm{~s}$ dwell as shown in Figure 2a. In order to obtain lattice strains 
to assess residual stresses, a measurement of stress-free lattice spacing, or $d_{h k l}^{0}$, is required [24]. Following neutron diffraction measurements of an intact $0 \mathrm{~s}$ dwell wall and an intact $40 \mathrm{~s}$ dwell wall, a $5 \mathrm{~mm}$ thick slice was cut from the center of each of the four walls by electrical discharge machining $(E D M)$ as shown in Figure 2a. These extracted slices were then cut into a comb pattern to relieve residual stresses in the vertical direction as shown in Figure 2c. These slices are referred throughout as the reference samples. The stresses in the length direction were assumed to be relieved upon sample extraction as the thickness of the slice was $5 \mathrm{~mm}$, and the stresses in the thickness direction were assumed to be negligible as the unsliced middle region of the comb pattern was less than $5 \mathrm{~mm}[14]$.

To study the influence of heat treatment on the measured $d_{h k l}^{0}$ values, one set of these slices (i.e., one slice from a $0 \mathrm{~s}$ dwell wall, and one slice from a $40 \mathrm{~s}$ dwell wall) was annealed at 870 ${ }^{\circ} \mathrm{C}$ in argon for $1 \mathrm{~h}$, a typical condition for stress relief without recrystallization in Inconel 625 [25]. The other set of two thin slices was not subjected to a stress-relieving heat treatment.

For measurement of the lattice spacings in the walls and reference samples, sampling volumes of approximately $(2 \mathrm{~mm})^{3}$ were used. Fifteen points were examined in the intact walls and the extracted combs: six locations in the baseplate, eight locations in the build, and one location at the intersection between the build and baseplate (see Figure 2b). At each position, the diffraction signals were collected for approximately ten minutes to obtain good counting statistics. 
(a)

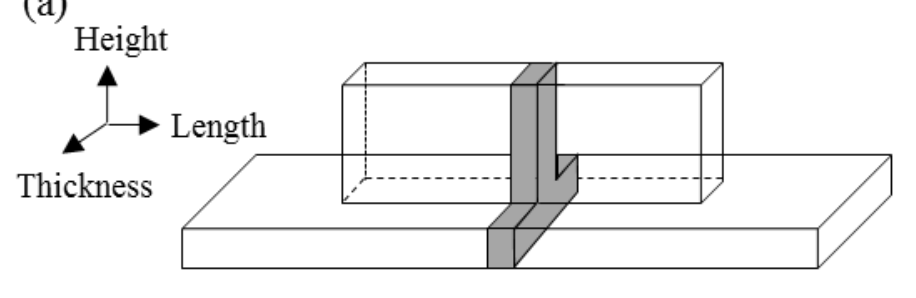

(b)

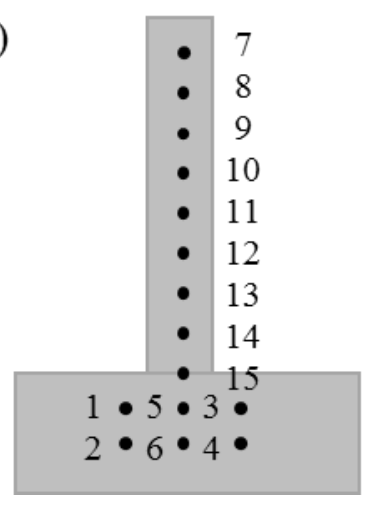

(c)

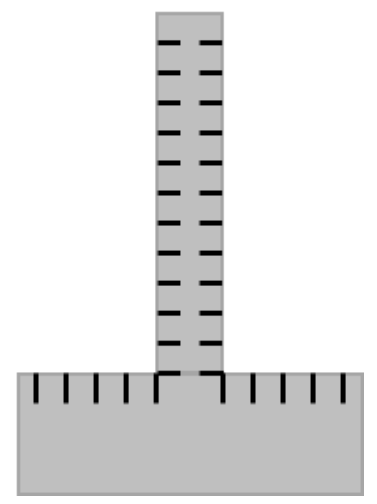

Figure 2. (a) Schematic of the Inconel 625 additively manufactured wall. The shaded region is that from which strains were measured in the intact walls, and also the region that was extracted from the walls for measurement of strain- and stress-free $d_{h k l}^{0}$ values. (b) Schematic showing positions where neutron diffraction measurements were made in the central plane of intact walls, and where corresponding measurements were taken in the stress-free reference slices, with six measurements from the baseplate, eight from the wall, and one at the interface between the wall and baseplate. (c) Schematic of a slice extracted from a wall and subsequently cut into a comb pattern, where cuts are indicated by black lines, to mechanically relieve residual stress.

Neutron diffraction measures lattice spacing based on Bragg's law:

$$
\lambda=2 d_{h k l} \sin \theta_{h k l}
$$

where $\theta_{h k l}$ is the angle between the incident beam and the (hkl) lattice plane, $d_{h k l}$ is the lattice spacing of the $(\mathrm{hkl})$ plane of interest, and $\lambda$ is the incident neutron wavelength determined by time of flight according to the de Broglie relation:

$$
h / \lambda=m L / t
$$


where $h$ is Planck's constant, $m$ is the neutron mass, $L$ is the length of the neutron flight path, and $t$ is time of flight, or the time it takes for a neutron to travel from the source to the detector. Combining equations (1) and (2), the lattice spacing as a function of the neutron time of flight is given as:

$$
d_{h k l}=\frac{h t}{2 m L \sin \theta_{h k l}} .
$$

Residual lattice strains, $\varepsilon_{h k l}$, can be computed from the shift in lattice spacing $d_{h k l}$ from the stress-free lattice spacing, $d_{h k l}^{0}$, using the following equation:

$$
\varepsilon_{h k l}=\frac{d_{h k l}-d_{h k l}^{0}}{d_{h k l}^{0}} .
$$

Based on the symmetry of the walls, it is assumed that the three principal stresses are oriented along the length $\left(\mathrm{x}_{1}\right)$, height $\left(\mathrm{x}_{2}\right)$, and thickness $\left(\mathrm{x}_{3}\right)$ of the wall. Therefore, the normal residual stresses, $\sigma_{11}, \sigma_{22}$, and $\sigma_{33}$, can be calculated using Hooke's law:

$$
\begin{aligned}
& \sigma_{11}=\frac{E_{h k l}}{1+v_{h k l}}\left\{\varepsilon_{11}+\frac{v_{h k l}}{1-2 v_{h k l}}\left(\varepsilon_{11}+\varepsilon_{22}+\varepsilon_{33}\right)\right\} \\
& \sigma_{22}=\frac{E_{h k l}}{1+v_{h k l}}\left\{\varepsilon_{22}+\frac{v_{h k l}}{1-2 v_{h k l}}\left(\varepsilon_{11}+\varepsilon_{22}+\varepsilon_{33}\right)\right\} \\
& \sigma_{33}=\frac{E_{h k l}}{1+v_{h k l}}\left\{\varepsilon_{33}+\frac{v_{h k l}}{1-2 v_{h k l}}\left(\varepsilon_{11}+\varepsilon_{22}+\varepsilon_{33}\right)\right\},
\end{aligned}
$$

where $E_{h k l}$ and $v_{h k l}$ are $h k l$ diffraction peak-specific Young's modulus and Poisson's ratio, and $\varepsilon_{11}, \varepsilon_{22}$ and $\varepsilon_{33}$ are lattice strains calculated from Eqn. (4).

Residual stresses can be classified into two scales: macrostresses, or type I stresses, whose length scales are comparable to the dimension of samples, and intergranular, or type II stresses, whose length scale is on the order of grains. Macrostresses are relieved in small cubes or combs 
extracted from samples. Intergranular stresses still exist in small stress-free samples and result from plastic anisotropy in grains, or the fact that crystallographic slip is preferred in certain slip systems. Therefore, to compute macroscopic residual stresses, it is important to select an (hkl) plane that is least affected by intergranular stresses, so that it accurately reflects the macroscopic stress state $[7,9,26]$.

In fcc Ni based alloys, such as Inconel 625, intergranular stresses have little influence on the $\{311\}$ planes, meaning that the stresses computed using the $\{311\}$ planes are representative of the macroscopic residual stresses in these systems [27]. Therefore, only $d_{311}$ and $d_{311}^{0}$ measured by neutron diffraction were used in lattice strain and residual stress calculations. Both $d_{311}$ and $d_{311}^{0}$ are extracted from neutron diffraction data using VDRIVE software [28]. The elastic constants $E_{311}$ and $v_{311}$ were taken to be $193.8 \mathrm{GPa}$ and 0.305 for the annealed Inconel 625 baseplate, 156.3 GPa and 0.366 for Inconel 625 walls made by AM [29].

\section{Thermomechanical Simulations}

Reference [30] provides a detailed review of the finite element modeling of residual stress and distortion for welding and AM processes. In the present work, Lagrangian reference frames are utilized. A transient thermal analysis is performed, sequentially followed by an elastoplastic mechanical analysis.

\subsection{Modeling Physics}

The governing equation for transient heat conduction for a component subject to a volumetric heat source is given as: 


$$
Q(x, t)-\nabla \cdot q(x, t)=\rho C_{P} \frac{d T}{d t}
$$

where $\rho$ is the material density, $C_{P}$ is the temperature dependent specific heat capacity, $T$ is the temperature, $t$ is the time, $Q$ is the time- and location-dependent volumetric heat source, $x$ is the relative reference coordinate, and $q$ is the conductive heat flux through the material. The Fourier heat flux constitutive relation describes the flow of heat through a solid body, and is given as:

$$
q=-k \nabla T
$$

where $k$ is the temperature-dependent thermal conductivity.

The Stefan-Boltzmann law is used to calculate the thermal radiation $q_{\mathrm{rad}}$, and is given as:

$$
q_{\text {rad }}=8 \sigma_{b}\left(T_{S}^{4}-T_{\infty}^{4}\right)
$$

where $\varepsilon$ is the surface emissivity, $\sigma_{b}$ is the Stefan-Boltzmann constant, $T_{S}$ is the surface temperature of the workpiece, and $T_{\infty}$ is the ambient temperature.

Newton's law of cooling accounts for the convective heat loss $q_{c o n v}$, and is given as:

$$
q_{\text {conv }}=h\left(T_{S}-T_{\infty}\right),
$$

where $h$ is the convective heat transfer coefficient.

The governing mechanical stress equilibrium equation is given as:

$$
\nabla \cdot \sigma=0
$$

where $\sigma$ here is the third order stress tensor.

The mechanical constitutive law is:

$$
\sigma=C \varepsilon_{e}
$$

where $C$ is the fourth order stiffness tensor, and $\varepsilon_{e}$ is the second order elastic strain tensor. Assuming small deformation thermo-elasto-plasticity, the total strain, $\varepsilon$, can be decomposed into the sum of the elastic, $\varepsilon_{e}$, plastic, $\varepsilon_{p}$, and thermal, $\varepsilon_{T}$, strains, as: 


$$
\varepsilon=\varepsilon_{e}+\varepsilon_{p}+\varepsilon_{T}
$$

\subsection{Numerical Implementation}

Figure 3a illustrates the finite element mesh used for the analyses. The mesh was composed of 52,472 Hexagonal-8 elements and 62,231 nodes. The mesh density in the deposition region

was 2 elements per heat source radius. A 3-step mesh convergence study was performed to confirm that the mesh was sufficiently fine. The thermomechanical analysis was performed using the finite element solver Project Pan (Autodesk Inc, State College, PA). Table 1 [31] lists the temperature-dependent thermal and mechanical properties used for Inconel 625.

The heat source boundary condition, Q, was applied using Goldak's double ellipsoid model [32]. Convection and radiation were applied to all free surfaces of the mesh. The calibrated convection coefficient, $h$, and surface emissivity, $\varepsilon$, were assigned as $18 \mathrm{~W} / \mathrm{m}^{2} /{ }^{\circ} \mathrm{C}$ and 0.28 [33], respectively. The addition of material into the simulation was modeled using the hybrid quietinactive element activation approach [34]. 
Table 1. Temperature dependent thermal properties of Inconel 625 where $T$ is the temperature, $K_{s}$ is the thermal conductivity, $C_{p}$ is the specific heat, $E$ is the Young's modulus, $\sigma_{y}$ is the yield strength, and $\alpha$ is the coefficient of thermal expansion [31].

\begin{tabular}{|c|c|c|c|c|c|}
\hline $\boldsymbol{T}\left({ }^{\circ} \mathbf{C}\right)$ & $\boldsymbol{K}_{\boldsymbol{s}}\left(\mathbf{W} / \mathbf{m} /{ }^{\circ} \mathbf{C}\right)$ & $\boldsymbol{C}_{p}(\mathbf{J} / \mathbf{k g})$ & $\boldsymbol{E}(\mathbf{G P a})$ & $\boldsymbol{\sigma}_{\mathbf{y}}(\mathbf{M P a})$ & $\boldsymbol{\alpha}\left(\boldsymbol{\mu} \mathbf{m} / \mathbf{m}^{\circ} \mathbf{C}\right)$ \\
\hline 20 & 9.9 & 410 & 208 & 493 & 12.8 \\
\hline 93 & 10.8 & 427 & 204 & 479 & 12.8 \\
\hline 205 & 12.5 & 456 & 198 & 443 & 13.1 \\
\hline 315 & 14.1 & 481 & 192 & 430 & 13.3 \\
\hline 425 & 15.7 & 511 & 186 & 424 & 13.7 \\
\hline 540 & 17.5 & 536 & 179 & 423 & 14.0 \\
\hline 650 & 19.0 & 565 & 170 & 422 & 14.8 \\
\hline 760 & 20.8 & 590 & 161 & 415 & 15.3 \\
\hline 870 & 22.8 & 620 & 148 & 386 & 15.8 \\
\hline
\end{tabular}

\section{Results and Discussion}

After the $d_{311}^{0}$ at each measured point was obtained from neutron diffraction, the average values for $d_{311}^{0}$ along the length and thickness directions of the baseplate, denoted as $d_{311, \text { base }}^{0}$, and of the wall made by AM, denoted as $d_{311, A M}^{0}$, were also calculated as the average of $d_{311}^{0}$ at points 1-6 and points 7-14 in Figure 2b, respectively. Since all walls were built on annealed Inconel 625 baseplates, $d_{31 \text { base }}^{0}$ should be the same for all samples. Point 15 was at the interface of the baseplate and the wall, so the average of $d_{31 \text {,base }}^{0}$ and $d_{311, A M}^{0}$ was used as the average $d_{311}^{0}$ for point 15 .

The below methods were used to find $d_{h k l}^{0}$ in order to determine the best method for computing residual stresses using neutron diffraction: 
(1) Measure $d_{h k l}^{0}$ from the reference samples that were not heat treated, and use the $d_{h k l}^{0}$ value for each point in the reference sample to compute the stress at the corresponding point in the intact wall.

(2) Measure $d_{h k l}^{0}$ from the reference samples that were not heat treated, and use an average $d_{h k l}^{0}$ for the wall, and an average $d_{h k l}^{0}$ for the baseplate, to compute the stresses in the intact walls.

(3) Measure $d_{h k l}^{0}$ from the heat treated reference samples, and use the $d_{h k l}^{0}$ value for each point in the reference sample to compute the stress at the corresponding point in the intact wall.

(4) Measure $d_{h k l}^{0}$ from the heat treated reference samples, and use an average $d_{h k l}^{0}$ for the wall, and an average $d_{h k l}^{0}$ for the baseplate, to compute the stresses in the intact walls.

Figures $3 b$ and $3 c$ are $2 \mathrm{D}$ stress contours, of the normal stress along the length direction predicted by the thermomechanical simulations. To compare the simulation results with the experimentally calculated stresses, the stress at the node in the simulation nearest to the measurement location in the experiment (shown in Figure 2b) was compared to the corresponding experimentally obtained value. Figure 4 shows a comparison of the residual stress along the length direction as a function of position predicted by simulations and measured experimentally taking the $d_{311}^{0}$ measurement from the reference samples not subjected to stressrelieving heat treatment, using the measured $d_{311}^{0}$ at each position (analysis method 1), or the average $d_{311}^{0}$ in the build to compute strains in the wall, and the average $d_{311}^{0}$ in the baseplate to compute strains in the baseplate (analysis method 2). The uncertainty in the stress measurement at each location, $u_{\sigma l}$, was determined using a propagation of uncertainty approach, taking into 
consideration the resolution, or uncertainty of the $d_{311}^{0}$ measurement, $\delta d_{311}^{0}$, the uncertainty of the $d_{311}$ measurement, $\delta d_{311}$, and the uncertainty of the strain calculation, $u_{\varepsilon}$, using the following equations $[20,35]$ :

$$
\begin{aligned}
& u_{\varepsilon}=\frac{1}{d_{h k l}^{0}}\left[\left(\delta d_{h k l}\right)^{2}+\left(\delta d_{h k l}^{0}\right)^{2}\right]^{\frac{1}{2}} \\
& u_{\sigma 1}=\left[\left(\frac{E_{h k l}}{\left(1+v_{h k l}\right)} u_{\varepsilon 1}\right)^{2}+\left(\frac{v E_{h k l}}{\left(1+v_{h k l}\right)\left(1-2 v_{h k l}\right)}\right)^{2}\left(u_{\varepsilon 1}{ }^{2}+u_{\varepsilon 2}{ }^{2}+u_{\varepsilon 3}{ }^{2}\right)\right]^{\frac{1}{2}},
\end{aligned}
$$

where $E_{h k l}$ and $v_{h k l}$ are $h k l$ diffraction peak-specific Young's modulus and Poisson's ratio, respectively, and $u_{\varepsilon 1}, u_{\varepsilon 2}$ and $u_{\varepsilon 3}$ are strain uncertainties along the length, height, and thickness directions, respectively, as calculated from Eqn. (15).

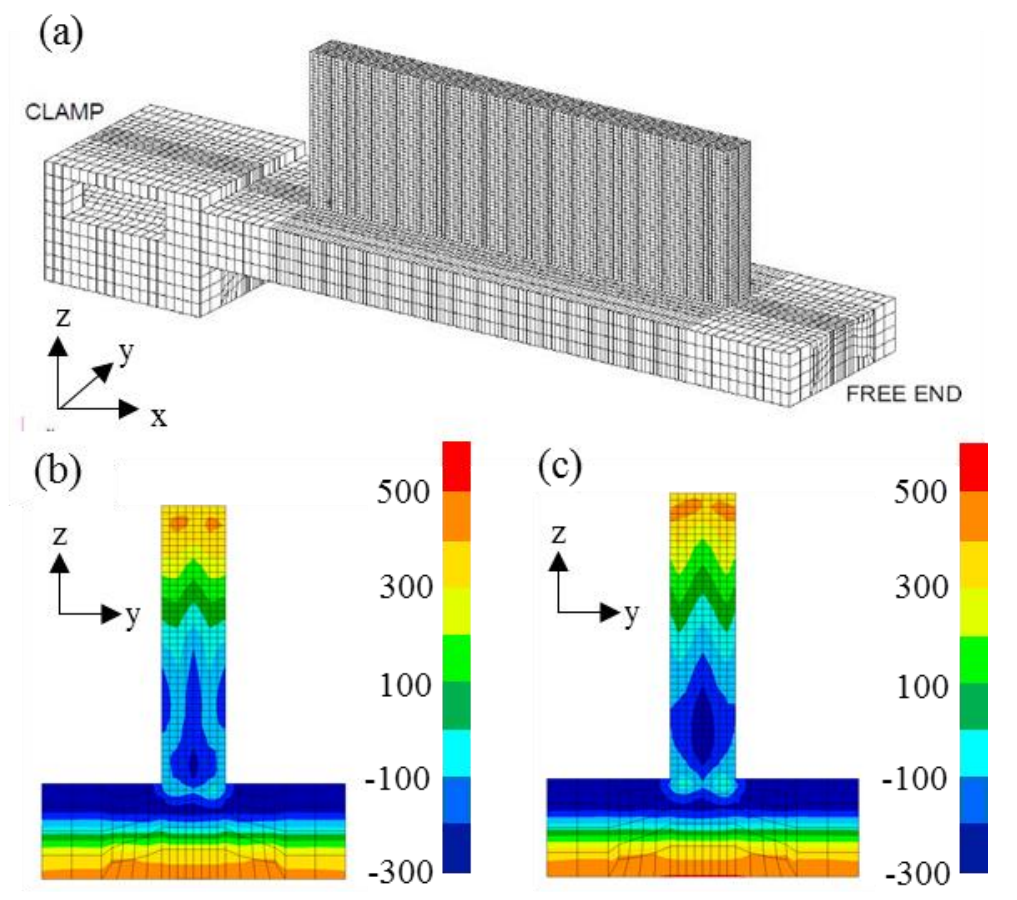

Figure 3. (a) Schematic of finite element mesh of an Inconel 625 additively manufactured wall. (b) $2 \mathrm{D}$ residual stress contours along length direction of the Inconel 625 wall with $0 \mathrm{~s}$ dwell time between layers. (c) 2D residual stress contours along length direction of the Inconel 625 wall with $40 \mathrm{~s}$ dwell time between layers. 

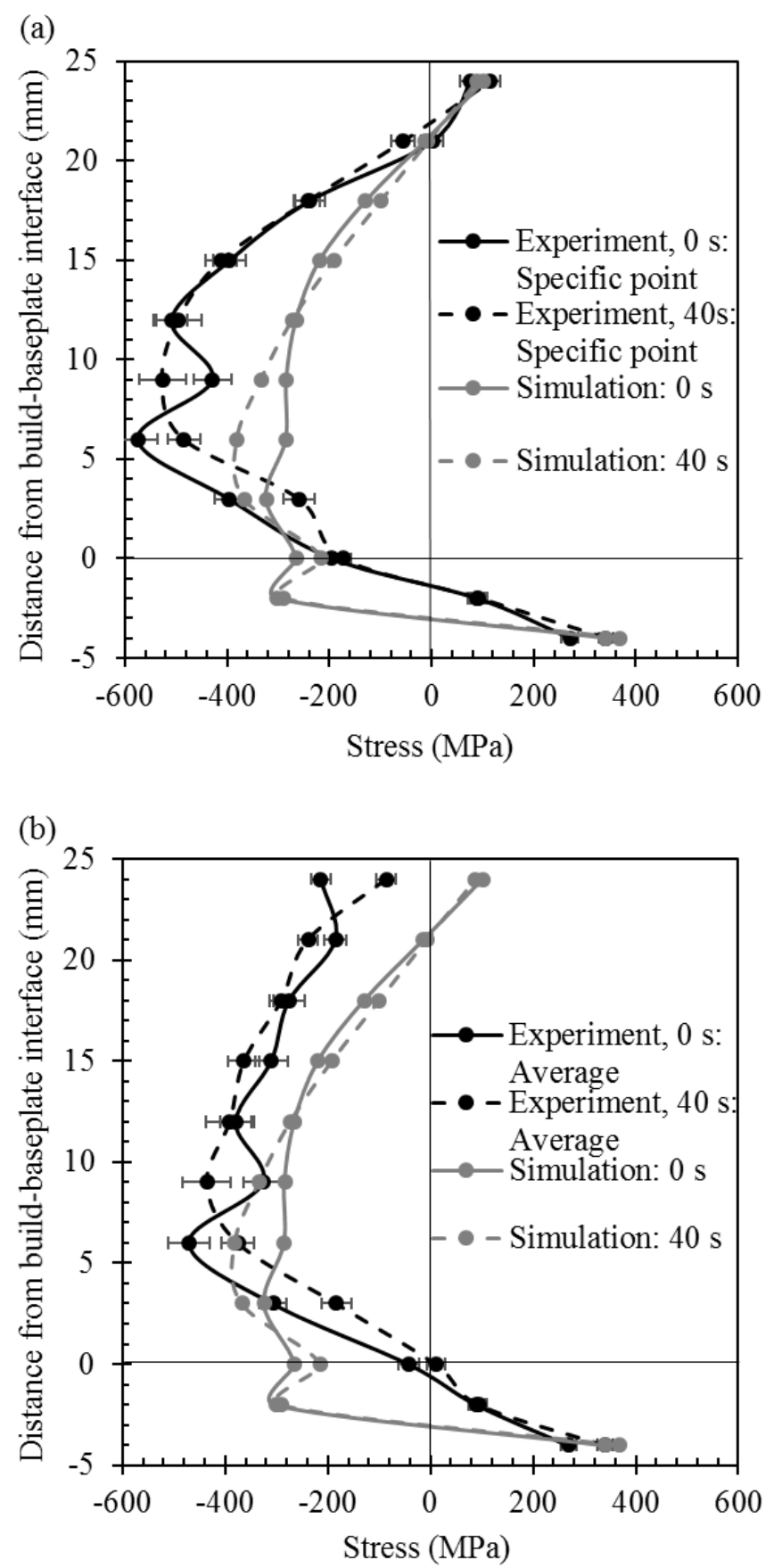

Figure 4. Residual stresses in the length direction in the center plane of the build as a function of distance from the build-baseplate interface predicted by thermomechanical simulations (gray) and compared with stresses calculated with neutron diffraction (black) using (a) $d_{311}^{0}$ at each measured point (analysis method 1), and (b) average $d_{311}^{0}$ (analysis method 2) in reference samples without heat treatment. 
The thermomechanical simulations predict that the two walls made with different dwell times have similar stress versus position trends and values. Both walls were found to have slightly compressive stresses in the transition region between the baseplate and the wall, and tensile stresses at the top of the wall, in line with [36,37]. The experimentally measured values agree with the trends found in the simulations of these walls. In particular, when using the reference samples that were not heat treated, the residual stresses in the most of the build are computed to be compressive, which is in good agreement with the predictions of the thermomechanical modeling in both walls with different dwell times. Using the measured $d_{311}^{0}$ at each position from reference samples that have not been heat treated is the most well-accepted method to measure residual stresses using neutron diffraction. Its good agreement with thermomechanical results (Figure 4a) indicates that neutron diffraction and thermomechanical simulations are complementary techniques in determining residual stresses. Additionally, this agreement demonstrates that high-fidelity thermomechanical modeling can be used to predict residual stresses during DED AM in order to optimize processing parameters to reduce residual stresses and to minimize distortion, prior to building components.

The discrepancy between experimental and simulation results in Figure 4 may be partly attributed to the strong texture $<200>$ along the length direction in the AM Inconel 625 samples as measured by electron backscatter diffraction (EBSD; Oxford Nordlys Max2) [38]. The thermomechanical simulations presented here do not consider this anisotropy, but assume material isotropy.

Figure 5 shows the computed residual stresses along the length direction as a function of position using data from the heat treated reference slices and $d_{311}^{0}$ at each measured point (Figure 5a, analysis method 3) and the average $d_{311}^{0}$ values (Figure 5b, analysis method 4). With these 
two analysis methods, the residual stresses calculated from neutron diffraction data in the baseplate roughly follow the trend of the simulations in both samples, as shown in Figures 5a and $5 \mathrm{~b}$. However, there are large discrepancies between the predictions and calculations of stresses in the build. The simulations predict that the residual stresses in the build are tensile at the top of the wall, and transition to compression as the distance to the baseplate decreases.

However, when using the $d_{311}^{0}$ measurements taken from the heat treated reference samples, the computed residual stresses in the build and baseplate are all tensile. This result of only tensile stresses acting along the centerline of the wall in the length direction would not satisfy equilibrium, and thus, this analysis approach of using heat treated reference samples for $d_{311}^{0}$ cannot be correct. 

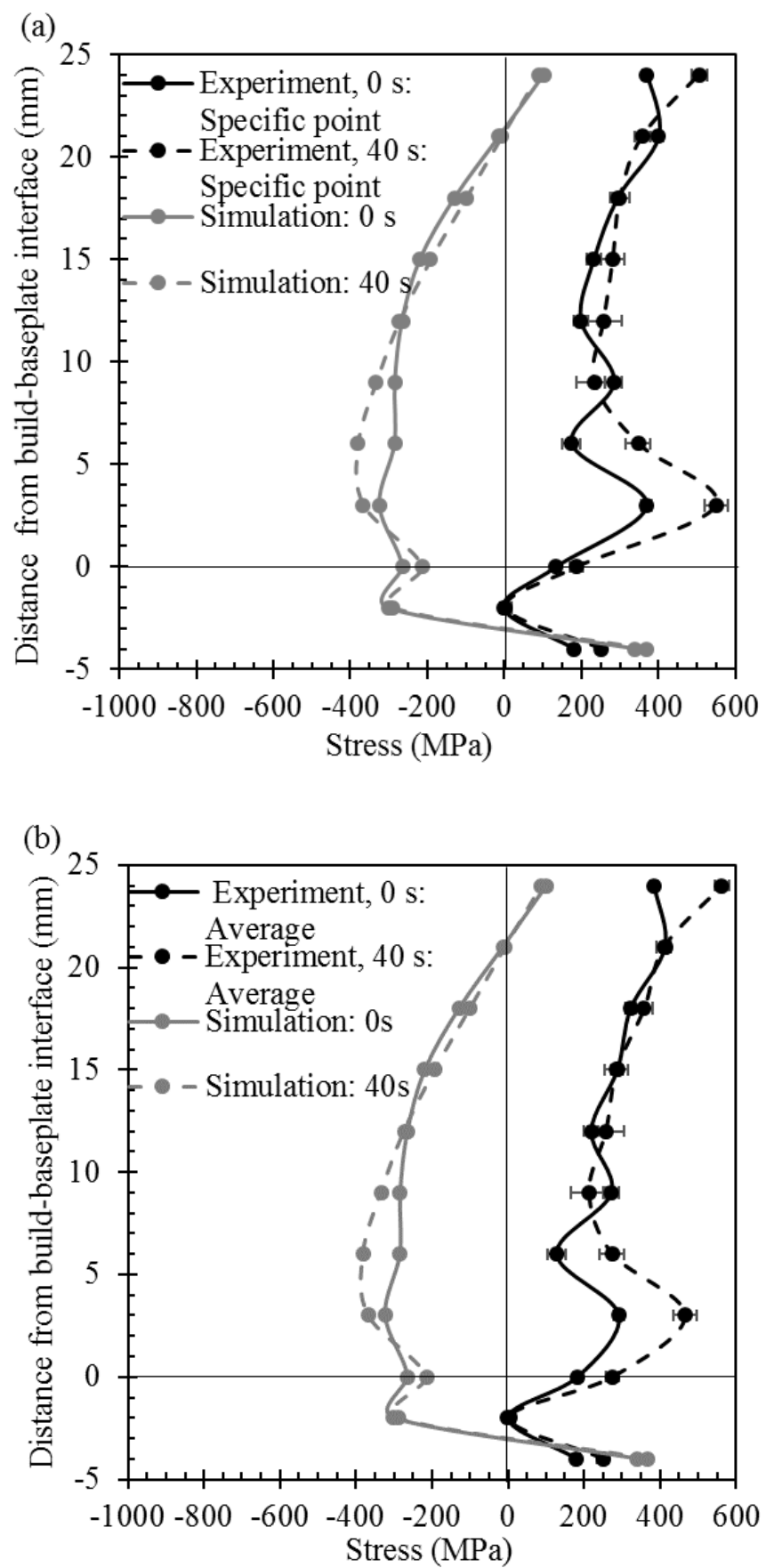

Figure 5. Residual stresses in the length direction in the center plane of the build as a function of distance from the build-baseplate interface predicted by thermomechanical simulations (gray) and compared with stresses calculated with neutron diffraction (black) using (a) $d_{311}^{0}$ at each measured point (analysis method 3), and (b) average $d_{311}^{0}$ (analysis method 4) in reference samples subjected to stress-relief heat treatment. 
Figure 6 shows a comparison of the residual stress along the height direction as a function of position from simulations and experimental results using $d_{311}^{0}$ from analysis methods 1 and 2 . These experimental values also agree well with the thermomechanical predictions. There is a discrepancy between the predicted and experimentally measured residual stresses at the transition region between the baseplate and the wall as well as at the top of the wall in Figure 6a. This difference may be due to the $<220>$ texture along the height direction of the build compared to no texture in the annealed baseplate [39]. Texture varies with position in the build because the largest thermal gradient during solidification dictates grain morphology and direction, and this gradient depends on position within the wall. For example, in the topmost layers, the largest thermal gradient during solidification is along the thickness direction, since these layers are not subjected to numerous reheating cycles, whereas lower in the build, as layers are reheated multiple times, the largest thermal gradient is in the height direction [39]. Figure 7 shows the computed residual stress along the height direction as a function of position using $d_{311}^{0}$ from analysis methods 3 and 4. Similar with Figure 5, the calculated stresses in both the build and baseplate are tensile in the height direction, which does not satisfy equilibrium. Due to the small thickness of the builds $(7 \mathrm{~mm})$, the residual stresses along the thickness direction are significantly smaller than in the other two directions, with an average predicted absolute value of $60 \mathrm{MPa}$, which is on the order of the uncertainty in the stress measurements by neutron diffraction. Therefore, residual stresses along the thickness direction were not computed. 


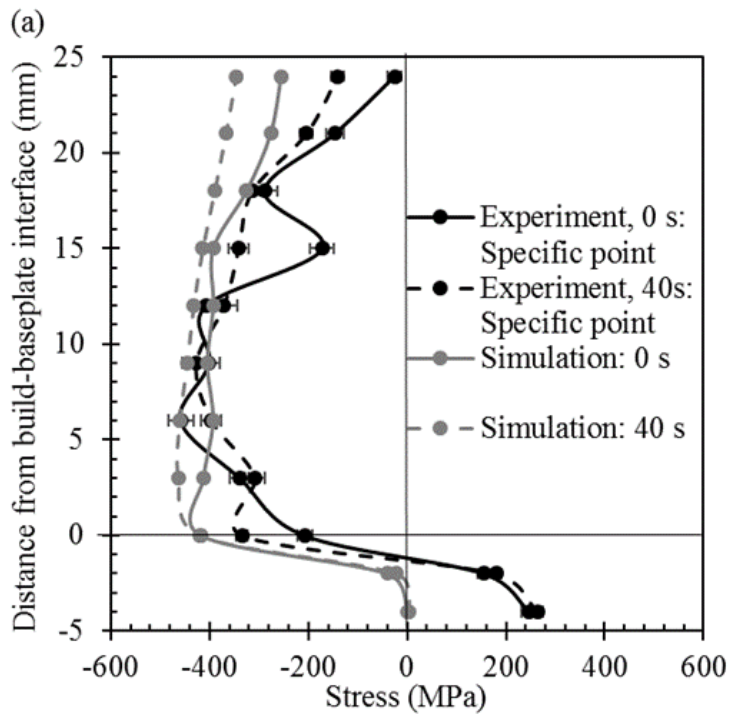

(b)

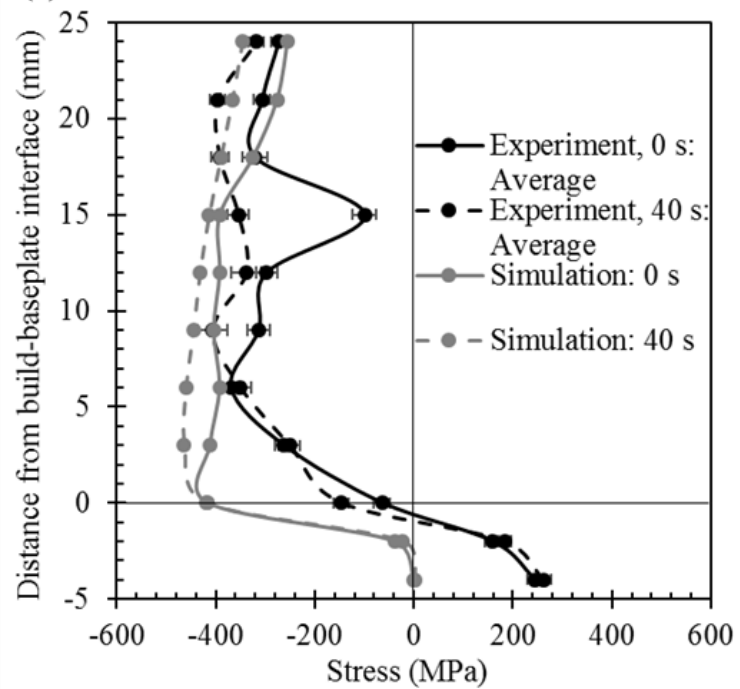

Figure 6. Residual stresses in the height direction in the center plane of the build as a function of distance from the build-baseplate interface predicted by thermomechanical simulations (gray) and compared with stresses calculated with neutron diffraction (black) using (a) $d_{311}^{0}$ at each measured point (analysis method 1), and (b) average $d_{311}^{0}$ (analysis method 2) in reference samples without heat treatment. 

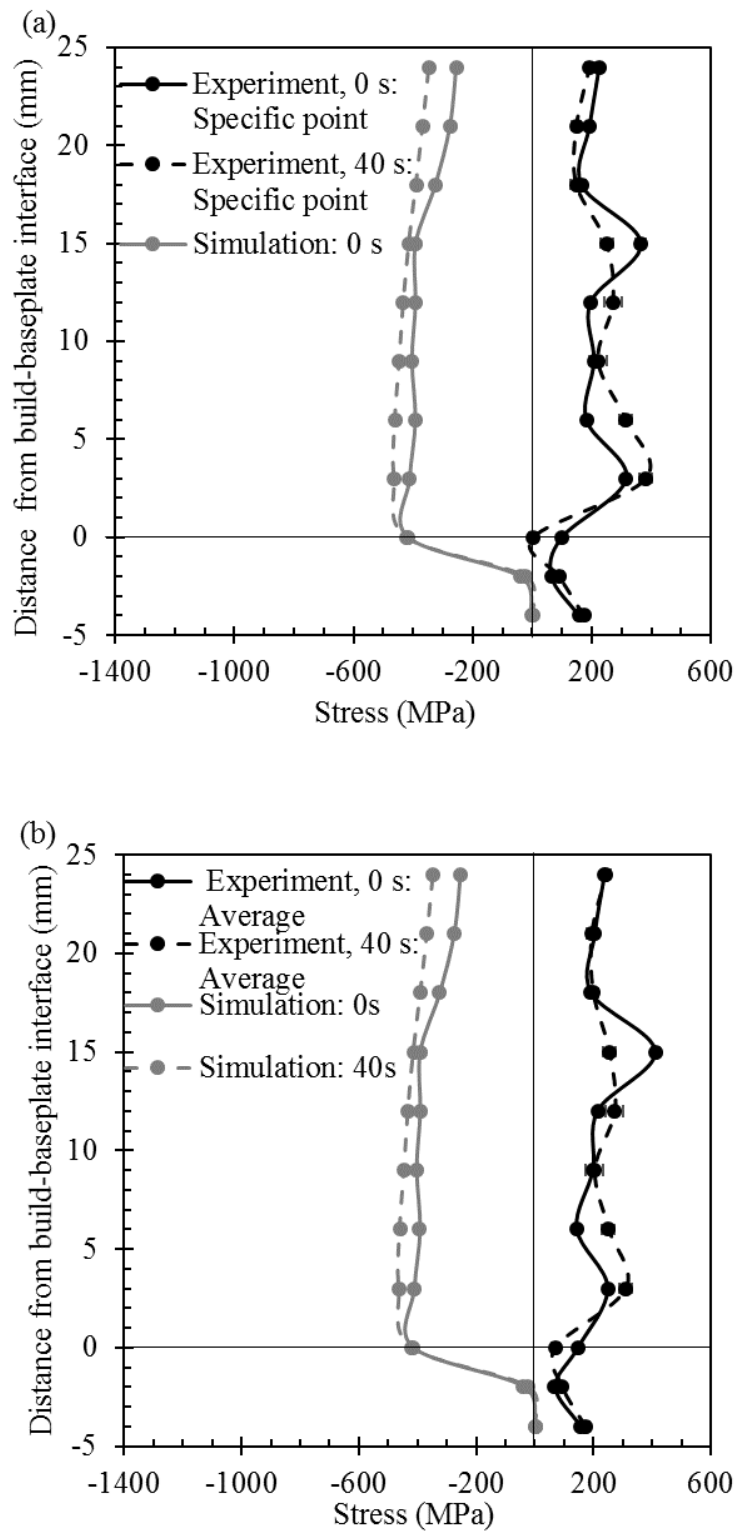

Figure 7. Residual stresses in the height direction in the center plane of the build as a function of distance from the build-baseplate interface predicted by thermomechanical simulations (gray) and compared with stresses calculated with neutron diffraction (black) using (a) $d_{311}^{0}$ at each measured point (analysis method 3), and (b) average $d_{311}^{0}$ (analysis method 4) in reference samples subjected to stress-relief heat treatment. 
The calculated tensile stresses in the build shown in Figures 5 and 7 indicate that the stressrelief heat treatment of the first set of reference samples leads to a decrease in $d_{311}^{0}$, likely due to small amounts of carbide precipitation during heat treatment [11]. Carbides tend to form when Inconel 625 is heated at $870{ }^{\circ} \mathrm{C}$ for $1 \mathrm{~h}$, which was the heat treatment performed to relieve stresses in the first set of reference samples [40]. The precipitation of carbides depletes the matrix of carbon, resulting in a lower lattice spacing in the heat-treated samples. Therefore, if using this smaller reference spacing to calculate strains and residual stresses, tensile residual stresses are calculated throughout the build.

We note that the measured $d_{311}^{0}$ values varied as a function of position in the build as shown in Figure 8. This spatial variation of the reference lattice spacing could be due to a slight chemical composition change with the deposition of additional layers during additive manufacturing. Wavelength dispersive spectroscopy (WDS; Cameca SXFive) was used to determine if there was a variation in chemical composition as a function of height in the build. As shown in Figure 9, the concentration of $\mathrm{Cr}$ decreases and those of $\mathrm{Nb}$ and Mo increase as the distance from the baseplate increases. In AM of metals, the most volatile elements within a material composition have the potential to be vaporized during deposition due to the high temperatures in the melt pool, meaning that the composition of the component may change as a function of position, especially as the temperature of the wall increases with distance from the baseplate as heat is retained with additional layers [41]. For Inconel 625, the most volatile element is $\mathrm{Cr}$ [42]; therefore, it is possible that during deposition, as the temperature of the build increases, and the temperature of the weld pool increases as well [41], Cr may be slightly depleted, which explains the decrease in at.\% of $\mathrm{Cr}$ (Figure 9a), as well as the decrease in reference lattice spacing (Figure 8) with increasing distance from the baseplate. The increase of 
$\mathrm{Nb}$ and Mo with height of the build can be explained by the Laves phase dissolving with increased build height, and therefore temperature. Laves phase, which is formed during rapid solidification in $\mathrm{AM}$, is rich in $\mathrm{Nb}$ and Mo. In $\mathrm{AM}$, previous layers are subjected to high temperature thermal cycles during the deposition of new layers. We postulate that as the temperature accumulates as the height of the walls increase, the amount of dissolved Laves phase increase with the distance from the baseplate [43], corresponding to an increase of $\mathrm{Nb}$ and $\mathrm{Mo}$ in the matrix (Figure 9b), which should result in an increase in lattice spacing. However, the total at. \% of $\mathrm{Nb}$ and $\mathrm{Mo}$ is much smaller than that of $\mathrm{Cr}$ so that the decrease of 4.5 at. \% of $\mathrm{Cr}$ has a more significant effect on lattice spacing than the increase of 1 at. $\%$ of $\mathrm{Nb}$ and 0.5 at. \% of Mo from the bottom to the top of the wall. The decrease of $\mathrm{Cr}$ from the bottom to the top of the wall in weight percent is about $1.5 \mathrm{wt}$. \%. Changes of composition less than $1 \mathrm{wt} . \%$ have a significant influence on equilibrium lattice spacing. For example, $0.1 \mathrm{wt} . \%$ change of carbon composition in steel gives a $0.09 \%$ change of the austenite lattice parameter [44]. As shown in Figure 8, the difference between measured reference lattice parameter from the bottom to the top of the wall with respect to the bottom of the wall is on the order of $0.06 \%$. Therefore, the slight variation of elemental composition with position had a significant influence on $d_{h k l}^{0}$. As $d_{h k l}^{0}$ decreases with the height, it is important to use location-dependent $d_{h k l}^{0}$ to compute residual stresses in components produced by AM. 


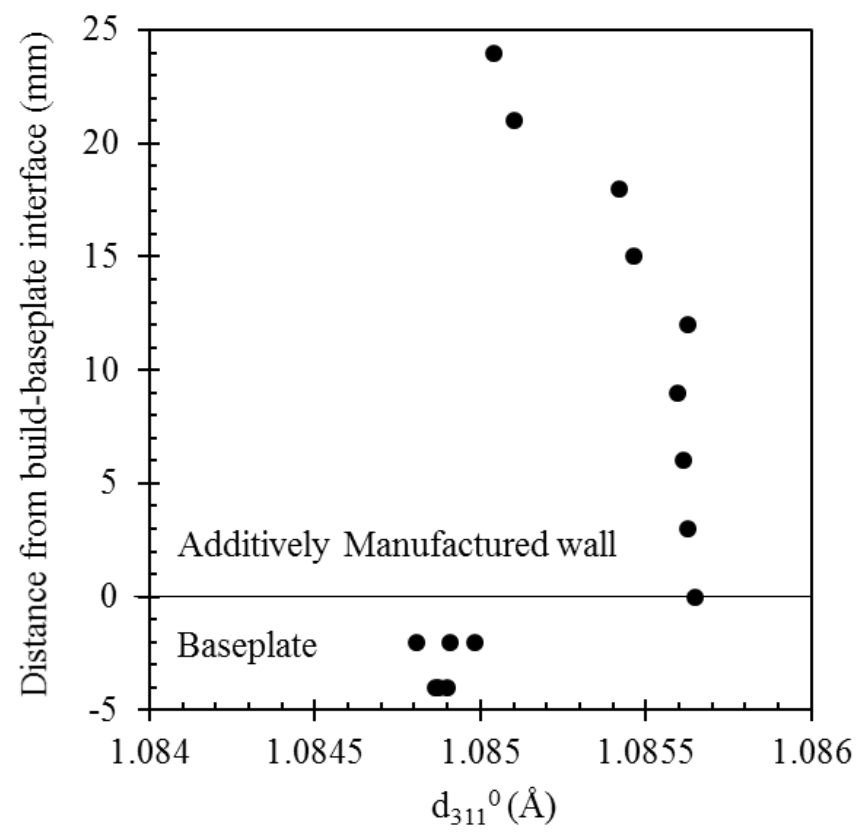

Figure 8. Reference $d_{311}^{0}$ as a function of distance from the build-baseplate interface measured by neutron diffraction in the stress-free reference samples without heat treatment.
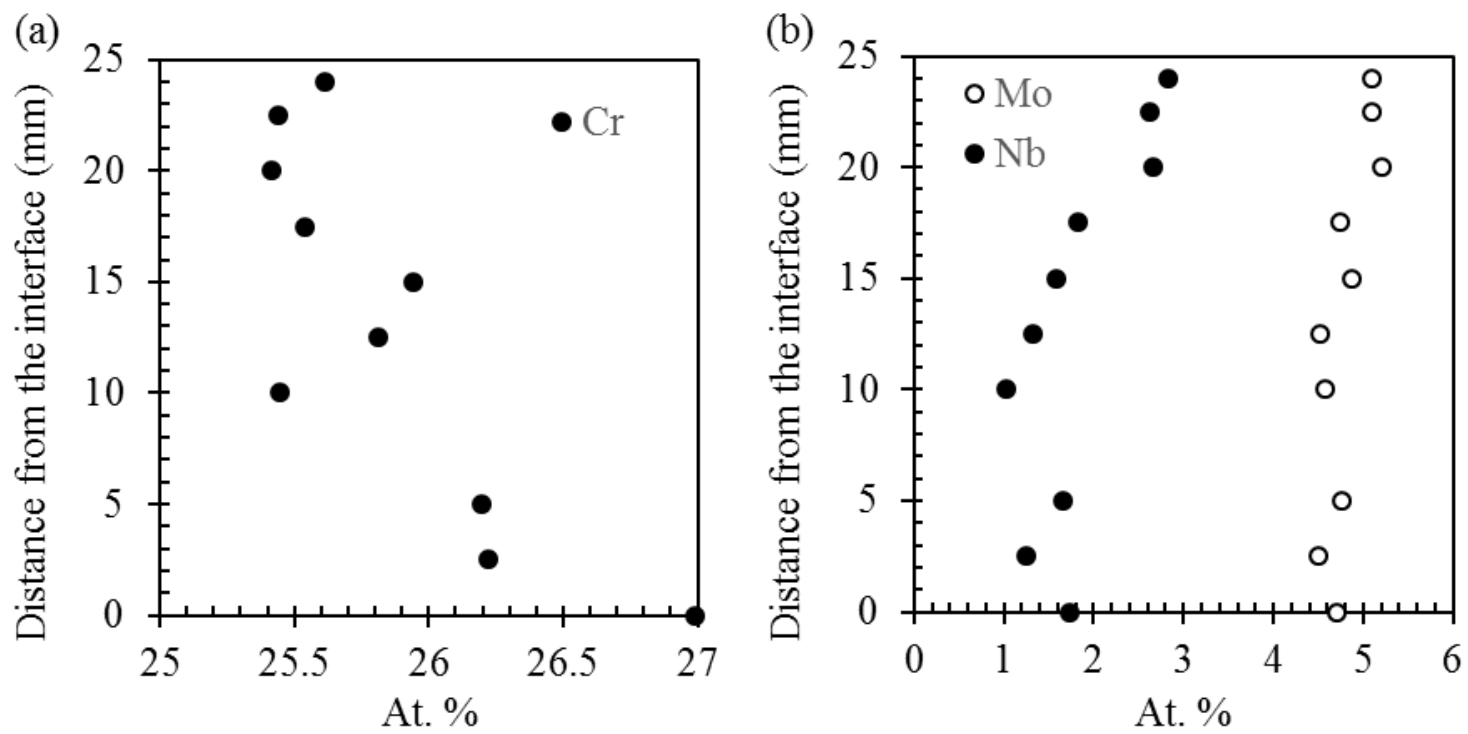

Figure 9. Elemental composition in atomic percentage (at. \%) of (a) $\mathrm{Cr}$, and (b) $\mathrm{Nb}$ and $\mathrm{Mo}$, as a function of distance from the baseplate in the $0 \mathrm{~s}$ dwell reference sample that was not heat treated. Results are from wavelength dispersive spectroscopy. 


\section{Summary and Conclusions}

This paper presents a method for using neutron diffraction to quantify residual stresses in materials, applied to additively manufactured Inconel 625 walls made with different processing parameters. The experimental results were compared to those from thermomechanical modeling. The primary contributions and conclusions of this work are as follows:

- We present a method for using neutron diffraction to measure and compute residual stresses in additively manufactured components, using an appropriate reference specimen for $d_{h k l}^{0}$ measurements. This experimental method can be used to validate, or can be augmented by, thermomechanical models, which predict continuum level residual stresses within an additively manufactured component. Therefore, neutron diffraction and modeling are complementary techniques in determining residual stresses and strains in AM builds.

- Extracting thin slices from builds, and mechanically stress relieving these samples through the addition of comb-type cuts into the slices is an appropriate way to relieve residual stress and measure reference $d_{h k l}^{0}$ values in neutron diffraction.

- While heat treatments may be used to relieve residual stresses, they modify the microstructure of the material, potentially changing the strain-free lattice spacings, and polluting neutron diffraction measurements of lattice strain. In the present work, it is postulated that the heat treatment applied led to the precipitation of carbides in the reference sample, reducing the measured strain-free lattice spacing, which led to errors in the computation of residual stress and strain using neutron diffraction. 
- The stress-free reference lattice spacings in additively manufactured and welded materials are location-dependent. As the temperature of the weld pool increases with height in AM, the most volatile elements vaporize, which leads to a depletion of those elements, and a corresponding decrease in reference lattice spacing, as the distance from the baseplate increases. The most volatile element in Inconel 625 is Cr. In additively manufactured Inconel 625, the concentration of $\mathrm{Cr}$, and correspondingly the reference lattice spacing, decreases as the distance from the baseplate increases. 


\section{Acknowledgments}

The authors gratefully acknowledge the financial support of the National Science Foundation through award number CMMI-1402978. Any opinions, findings, and conclusions or recommendations expressed in this material are those of the authors and do not necessarily reflect the views of the National Science Foundation. In addition, AMB acknowledges funding from the Oak Ridge Associated Universities Ralph E. Powe Junior Faculty Enhancement Award. The IN625 samples made by AM were fabricated at the Center for Innovative Materials Processing through Direct Digital Deposition (CIMP-3D). A portion of this research at ORNL's Spallation Neutron Source was sponsored by the Scientific User Facilities Division, Office of Basic Energy Sciences, U.S. Department of Energy. We thank Matthew Frost and Harley Skorpenske of ORNL for their technical support at the VULCAN beamline. 


\section{References}

[1] D.D. Gu, W. Meiners, K. Wissenbach, R. Poprawe, Laser additive manufacturing of metallic components: materials, processes and mechanisms, Int. Mater. Rev. 57 (2012) 133-164. doi:10.1179/1743280411Y.0000000014.

[2] J. Yu, M. Rombouts, G. Maes, Cracking behavior and mechanical properties of austenitic stainless steel parts produced by laser metal deposition, Mater. Des. 45 (2013) 228-235. doi:10.1016/j.matdes.2012.08.078.

[3] B.E. Carroll, T.A. Palmer, A.M. Beese, Anisotropic tensile behavior of Ti-6Al-4V components fabricated with directed energy deposition additive manufacturing, Acta Mater. 87 (2015) 309-320. doi:10.1016/j.actamat.2014.12.054.

[4] Z. Wang, T.A. Palmer, A.M. Beese, Effect of processing parameters on microstructure and tensile properties of austenitic stainless steel 304L made by directed energy deposition additive manufacturing, Acta Mater. 110 (2016) 226-235.

doi:10.1016/j.actamat.2016.03.019.

[5] P. Mercelis, J.-P. Kruth, Residual stresses in selective laser sintering and selective laser melting, Rapid Prototyp. J. 12 (2006) 254-265. doi:10.1108/13552540610707013.

[6] G.S. Schajer, Measurement of non-uniform residual stresses using the hole drilling method - part I: Stress calculation procedure, J. Eng. Mater. Technol. 110 (1988) 341343. doi:10.1115/1.3226059.

[7] P. Rangaswamy, M.L. Griffith, M.B. Prime, T.M. Holden, R.B. Rogge, J.M. Edwards, R.J. Sebring, Residual stresses in LENS components using neutron diffraction and contour method, Mater. Sci. Eng. A. 399 (2005) 72-83. doi:10.1016/j.msea.2005.02.019.

[8] R. Pynn, Neutron Scattering - A Non-destructive Microscope for Seeing Inside Matter, in: L. Liang, R. Romano, S. Helmut (Eds.), Neutron Appl. Earth, Energy Environ. Sci., Springer US, 2009: p. 2.

[9] P.J. Withers, M. Preuss, A. Steuwer, J.W.L. Pang, Methods for obtaining the strain-free lattice parameter when using diffraction to determine residual stress, J. Appl. Crystallogr. 40 (2007) 891-904. doi:10.1107/S0021889807030269.

[10] S. Pratihar, M. Turski, L. Edwards, P.J. Bouchard, Neutron diffraction residual stress measurements in a $316 \mathrm{~L}$ stainless steel bead-on-plate weld specimen, Int. J. Press. Vessel. Pip. 86 (2009) 13-19. doi:10.1016/j.ijpvp.2008.11.010.

[11] A.D. Krawitz, R.A. Winholtz, Use of position-dependent stress-free standards for diffraction stress measurements, Mater. Sci. Eng. A. 185 (1994) 123-130. doi:10.1016/0921-5093(94)90935-0.

[12] T. Holden, H. Suzuki, D. Carr, Macroscopic stress measurements by neutron diffraction and the part played by the stress-free reference, ISIJ Int. 46 (2006) 959-965. doi:10.2355/isijinternational.46.959.

[13] D. Thibault, P. Bocher, M. Thomas, M. Gharghouri, M. Côté, Residual stress characterization in low transformation temperature $13 \% \mathrm{Cr}-4 \% \mathrm{Ni}$ stainless steel weld by 
neutron diffraction and the contour method, Mater. Sci. Eng. A. 527 (2010) 6205-6210. doi:10.1016/j.msea.2010.06.035.

[14] R.J. Moat, A.J. Pinkerton, L. Li, P.J. Withers, M. Preuss, Residual stresses in laser direct metal deposited Waspaloy, Mater. Sci. Eng. A. 528 (2011) 2288-2298. doi:10.1016/j.msea.2010.12.010.

[15] P. Martinson, S. Daneshpour, M. Koçak, S. Riekehr, P. Staron, Residual stress analysis of laser spot welding of steel sheets, Mater. Des. 30 (2009) 3351-3359. doi:10.1016/j.matdes.2009.03.041.

[16] W. Zhang, Z. Feng, P. Crooker, Improved procedure for computing residual stresses from neutron diffraction data and its application to multipass dissimilar welds, Sci. Technol. Weld. Join. 16 (2011) 254-260. doi:10.1179/1362171810Y.0000000023.

[17] M. Preuss, J.W.L. Pang, P.J. Withers, G.J. Baxter, Inertia Welding Nickel-Based Superalloy: Part II. Residual Stress Characterization, Metall. Mater. Trans. A. 33 (2002) 3227-3234. doi:10.1007/s11661-002-0308-x.

[18] E.R. Denlinger, J.C. Heigel, P. Michaleris, T.A. Palmer, Effect of Inter-Layer Dwell Time on Distortion and Residual Stress in Additive Manufacturing of Titanium and Nickel Alloys, J. Mater. Process. Technol. 215 (2015) 123-131. doi:10.1016/j.jmatprotec.2014.07.030.

[19] K. An, H.D. Skorpenske, A.D. Stoica, D. Ma, X.L. Wang, E. Cakmak, First in situ lattice strains measurements under load at VULCAN, Metall. Mater. Trans. A Phys. Metall. Mater. Sci. 42 (2011) 95-99. doi:10.1007/s11661-010-0495-9.

[20] B. Clausen, D.W. Brown, I.C. Noyan, Engineering applications of time-of-flight neutron diffraction, JOM. 64 (2012) 117-126. doi:10.1007/s11837-011-0119-x.

[21] M.T. Hutchings, P.J. Withers, T.M. Holden, T. Lorentzen, Fundamentals of neutron diffraction, in: Intronduction to Charact. Residual Stress by Neutron Diffr., Talyor\&Francis Group, 2005: pp. 40-41.

[22] T. Ungar, A.D. Stoica, G. Tichy, X.-L. Wang, Orientation-dependent evolution of the dislocation density in grain populations with different crystallographic orientations relative to the tensile axis in a polycrystalline aggregate of stainless steel, Acta Mater. 66 (2014) 251-261. doi:10.1016/j.actamat.2013.11.012.

[23] G.M. Stoica, A.D. Stoica, M.K. Miller, D. Ma, Temperature-dependent elastic anisotropy and mesoscale deformation in a nanostructured ferritic alloy., Nat. Commun. 5 (2014) 18. doi:10.1038/ncomms6178.

[24] M.T. Hutchings, P.J. Withers, T.M. Holden, T. Lorentzen, Practical aspects of strain measurement using neutron diffraction, in: Intronduction to Charact. Residual Stress by Neutron Diffr., Talyor\&Francis Group, 2005: p. 155.

[25] M.J. Donachie, S.J. Donachie, Heat Treating, in: Superalloys A Tech. Guid., Second Edi, ASM International, 2002: p. 137.

[26] M.R. Daymond, The determination of a continuum mechanics equivalent elastic strain 
from the analysis of multiple diffraction peaks, J. Appl. Phys. 96 (2004) 4263-4272. doi:10.1063/1.1794896.

[27] W. Woo, Z. Feng, X.-L. Wang, S.A. David, Neutron diffraction measurements of residual stresses in friction stir welding: a review, Sci. Technol. Weld. Join. 16 (2011) 23-32. doi:10.1179/136217110X12731414739916.

[28] K. An, VDRIVE-Data Reduction and Interactive Visulaization Softwarew for Event Mode Neutron Diffraction, ORNL Report, Oak Ridge National Laboratory, 2012.

[29] Z. Wang, A.D. Stoica, D. Ma, A.M. Beese, Diffraction and single-crystal elastic constants of Inconel 625 at room and elevated temperatures determined by neutron diffraction, Mater. Sci. Eng. A. 674 (2016) 406-412. doi:http://dx.doi.org/10.1016/j.msea.2016.08.010.

[30] J.A. Goldak, M. Akhlaghi, Computational Welding Mechanics, Springer Science \& Business Media, 2006.

[31] INCONEL alloy 625, Spec. Met. Corp. (2013). http://www.specialmetals.com/documents/Inconel alloy 625.pdf (accessed August 30, 2016).

[32] J. Goldak, A. Chakravarti, M. Bibby, A new finite element model for welding heat sources, Metall. Trans. B. 15B (1984) 299-305. doi:10.1007/BF02667333.

[33] E.R. Denlinger, J.C. Heigel, P. Michaleris, Residual stress and distortion modeling of electron beam direct manufacturing Ti-6Al-4V, Proc. Inst. Mech. Eng. Part B J. Eng. Manuf. (2014). doi:10.1177/0954405414539494.

[34] P. Michaleris, Modeling metal deposition in heat transfer analyses of additive manufacturing processes, Finite Elem. Anal. Des. 86 (2014) 51-60. doi:10.1016/j.finel.2014.04.003.

[35] R.C. Wimpory, C. Ohms, M. Hofmann, R. Schneider, A.G. Youtsos, Statistical analysis of residual stress determinations using neutron diffraction, Int. J. Press. Vessel. Pip. 86 (2009) 48-62. doi:10.1016/j.ijpvp.2008.11.003.

[36] B.A. Szost, S. Terzi, F. Martina, D. Boisselier, A. Prytuliak, T. Pirling, M. Hofmann, D.J. Jarvis, A comparative study of additive manufacturing techniques: Residual stress and microstructural analysis of CLAD and WAAM printed Ti-6Al-4V components, Mater. Des. 89 (2016) 559-567. doi:10.1016/j.matdes.2015.09.115.

[37] F. Martina, M. Roy, P. Colegrove, Stewart W. Williams, Residual Stress Reduction in High Pressure Interpass Rolled Wire + Arc Manufacturing Ti-6Al-4V Components, in: Proc. 25 Th Int. Solid Free. Fabr. Symp, 2014: pp. 89-94.

[38] A.M. Beese, Z. Wang, A.D. Stoica, D. Ma, Absence of dynamic strain aging in an additively manufactured nickel-base superalloy, Submitt. Publ. under Revis. (2016).

[39] D. Ma, A.D. Stoica, Z. Wang, A.M. Beese, Crystallographic texture in an additively manufactured nickel-base superalloy, Submitt. Publ. under Revis. (2016). 
[40] S. Floreen, G.E. Fuchs, W.J. Yang, The Metallurgy of Alloy 625, in: Superalloys 718, 625, 706 Var. Deriv. Miner. Met. Mater. Soc., 1994: pp. 13-37.

doi:10.7449/1994/Superalloys_1994_13_37.

[41] V. Manvatkar, A. De, T. DebRoy, Spatial variation of melt pool geometry, peak temperature and solidification parameters during laser assisted additive manufacturing process, Mater. Sci. Technol. 31 (2015) 924-930.

doi:10.1179/1743284714Y.0000000701.

[42] T. Mukherjee, J.S. Zuback, A. De, T. DebRoy, Printability of alloys for additive manufacturing, Sci. Rep. 6 (2016) 1-8. doi:10.1038/srep19717.

[43] F. Xu, Y. Lv, Y. Liu, F. Shu, P. He, B. Xu, Microstructural Evolution and Mechanical Properties of Inconel 625 Alloy during Pulsed Plasma Arc Deposition Process, J. Mater. Sci. Technol. 29 (2013) 480-488.

[44] H.K.D.H. Bhadeshia, S.A. David, J.M. Vitek, R.W. Reed, Stress induced transformation to bainite in Fe-Cr-Mo-C pressure vessel steel, Mater. Sci. Technol. 7 (1991) 686-698. doi:10.1179/026708391790184915. 

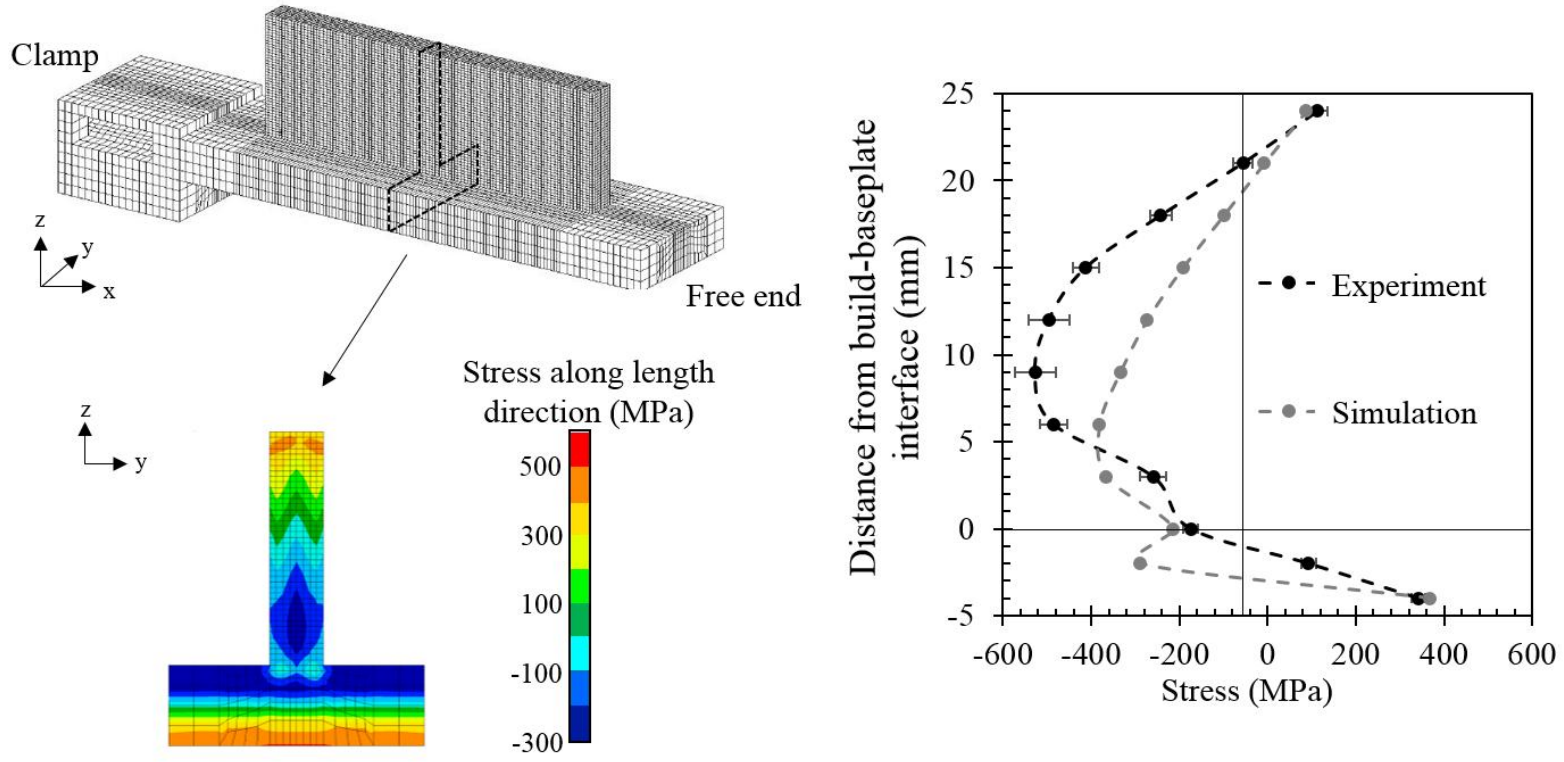